\title{
创新高校档案管理 服务地方经济转型
}

闵丽娟

哈尔滨华德学院

DOI:10.32629/mef.v2i9.247

[摘 要] 档案在政治、经济、科学、文化等诸多领域中具有重要价值,当前中国正处于转型发展的重要时期, 档案作为一种具 有特殊价值的信息资源对经济转型有着特殊且不可替代的作用。因此我们要创新档案管理,使其发挥资源优势为地方经济转 型服务。

[关键词] 档案; 创新; 经济; 转型

\section{Innovating University Archives Management, Serving Local Economic Transformation Min Lijuan Harbin Huade University}

[Abstract] Archives have important value in many fields such as politics, economy, science and culture, at present, China is in an important period of transformation and development. Archives as a special value information resource has a special and irreplaceable role in economic transformation. Therefore, we must innovate the archives management to make use of its resource advantages to serve the local economic transformation.

[Key words] archives; innovation; economy; transformation

高校是知识汇聚的地方, 主要从事教学、科研等活动, 发掘和利用其信息资源, 使其产生一定的经济效益, 从而促 进产教融合, 推动地方经济转型, 是档案工作者义不容辞的 责任, 而目前档案工作还存在许多不足, 这必将对经济转型 发展造成影响。

\section{1 高校档案工作现状}

首先, 档案人才素质有待提高。目前高校档案管理人员 素质和管理水平尚不能满足经济发展的需求, 档案意识不够, 管理水平相对薄弱, 在思想观念、业务水平上都与经济发展 需求有明显差距。

其次, 管理方式不能适应经济转型需要。传统的档案管 理方式已经无法适应新时期转型发展的需要。主要表现为: 制度体系尚不完善, 对信息共享重视不够, 档案资料的开发 利用不充分, 编研深度不够等。

再者, 技术落后制约工作发展。管理人员技术水平及现 代化处理能力都影响到信息资源的开发。经济快速发展, 积 极开发信息资源, 才能适应经济发展的需要, 才能使档案工 作充满生机和活力, 使档案事业持续发展。

档案工作的现状必会对地方经济转型造成影响。因此, 档案工作者要创新档案管理, 积极开发信息资源, 这样才能 适应经济社会发展的需要, 同时推动地方经济转型。

\section{2 档案管理创新的必要性}

当前中国正处于转型发展的重要时期, 随着 “大众创业, 万众创新” 的提出, 社会的各个领域都在创新, 高等教育的发 展也要求高校档案工作必须实现创新, 只有创新, 才能不断 推动档案工作向更高层次迈进, 适应和服务于社会各项事
业。因此我们要创新档案管理, 使其发挥资源优势为地方经 济转型服务。

2. 1 人才资源培养的需要。随着信息化的发展, 一方面要 对信息进行加工、重组, 形成新的信息资源, 另一方面要解决 档案管理中遇到的新技术、新问题。这就要求提高档案人员 的综合素质, 所以创新人才培养, 打造复合型人才, 建立适应 信息时代的档案管理队伍是必然要求。

2.2 市场经济建设发展的需要。为了适应经济发展要求, 档案的价值在原来传统功能的基础上, 进一步拓展与经济建 设相匹配。档案管理要想拓展就必须创新, 加强其价值功能 的研究与探索, 应当坚持了解社会需要、经济发展要求及市 场需求, 创新拓展档案管理, 最大化地为经济建设提供支撑。 这是适应市场经济建设发展的要求, 也是档案管理自身发展 的需要。

2. 3资源信息化的需要。档案是各种信息的真实记录, 是查考、决策的重要依据。在今天, 档案已由传统的 “文件” 转变为 “信息资源”, 在资源开发和经济建设等方面都有巨 大的价值和不可替代的作用。档案信息化建设是提高档案管 理水平、提升档案服务功能的迫切需要, 也是档案管理与时 俱进、不断创新的客观要求。

2.4响应国家政策的需要。根据国家发改委文件要求, 全国统一取消和免征33项行政事业性收费, 其中包括档案部 门的“利用档案收费”, 这就要求我们改变以往的利用模式, 广泛开发档案资源, 积极提供利用服务。创新机制, 要在保 留原有的运行模式的基础上, 逐步实现服务便捷化、功能社 会化。 
2.5 经济效益需求。档案管理的目的就是开发档案信息 资源, 提供利用服务。因此为了满足社会发展的需要, 必须充 分发挥档案的服务功能来推动档案管理的顺利开展。档案管 理向利用者提供服务, 使得档案信息进入社会各个领域。对 档案管理投资一定, 有效满足社会需求程度越大, 则效益越 高。因此, 要尽早认识到档案工作的重要性。

\section{3 档案管理如何实现创新}

随着转型发展的进一步深入, 档案工作只有不断的创新, 才能适应新时代发展的要求; 只有不断的创新, 才能向前发 展, 切实解决好人才培养、开放资源、服务地方等问题。为 此, 档案管理应加快创新, 主要体现在以下几个方面:

3.1 人才资源的创新。档案管理的创新, 先要人才创新, 要依靠人才推动, 促进人才发展。首先, 运用各种激励手段, 充分调动积极性, 发挥创造性, 增强凝聚力, 培养优秀团队; 其次, 通过各种途径, 加强档案工作人员的学习、培训, 通过 不断学习, 掌握科学、先进的工作方法, 提高工作业务水平, 适应新时期档案工作的需要; 再者, 敢于向传统观念挑战, 善于创新办法、拓展思路, 解决问题, 打破传统的管理模式, 充分挖掘内在潜力, 提高工作效率, 在档案业务上有所创新, 有所突破。

3. 2 思想观念的创新。思想观念创新是管理创新的前提, 要改变以往落后观念, 勇于探索实践, 有效地开创性地开展 工作; 保管档案的最终目的是利用档案, 积极进行信息转化, 把有效信息系统地、规范地整理出来, 才能更好的发挥档案 的信息作用, 体现档案的信息价值。因此, 把档案内容通过加 工整理变成更直接、更能发挥价值的信息, 是档案部门义不 容辞的职责。

3. 3管理方式的创新。虽然档案部门保管着丰富的信息 资源, 但我们仍该不断充实馆藏内容, 提高馆藏质量。有调 查、有计划地采集用户需要的信息资源, 并对档案资源不断 优化, 使其系统化、规范化、有序化, 及时、准确、高效地为 用户提供服务。构建与现代化相适应的档案管理体系, 完善 安全保管制度流程, 采用现代化科学管理方法, 对开放资源 进行网络信息检索, 从而为利用者提供方便快捷的服务。

3. 4 服务方式的创新。档案服务是档案管理的中心, 档案 管理通过服务才能发挥其应有的作用, 拓宽档案服务领域, 满足了社会不同层次利用者的需求。档案服务方式的创应新 注重加强和提高档案服务的主动性、针对性和及时性, 重视 和加强对档案利用者的研究, 不仅研究他们当前的需要, 还 应研究他们潜在的需求, 不仅限于目前的利用者, 还要挖掘 潜在的利用者, 以最大限度解决利用者利用档案的障碍, 以 利用者的需求和潜在需求来加强档案服务的创新。

3. 5 工作机制创新。注重机制的完善与创新。积极探索 和掌握新形势下档案工作的特点和规律, 建立健全有利于档 案管理和开发利用的良好机制, 以及有效调动档案工作者积 极性、创造性的相关机制。加快档案信息化工作, 全面推进
数字化建设。在做好规范化、标准化的基础上, 实现现代化、 数字化, 整合馆内信息资源, 为档案利用提供快捷方便的服 务平台, 为利用者提供真实可靠的信息依据, 为经济转型提 供帮助发挥有效作用。

\section{4 档案管理为经济转型服务}

目前, 我国档案工作正处于以服务民生为中心、保障事 业有力发展的新常态。我们必须拓宽思路, 提升服务的自觉 性, 推动档案工作向更高层次迈进, 使高校档案工作更好的 为经济转型服务。

解放思想, 更新观念, 找准档案服务的切入点和结合点, 努力实现从单纯保管向开放利用转变, 切实抓好工作重点, 力求在服务经济社会发展上有新作为。

档案管理是信息资源开发与利用的过程,如何方便快捷 地获取需要的档案信息, 实现信息资源互补, 是摆在许多企 业之间难以逾越的一道屏障。高校档案部门在做好校内服务 的同时, 还应拓展服务功能, 运用知识管理方法推动高校档 案数字化建设和服务方式转变, 加强档案信息化建设, 实现 资源共享互补。努力开放利用档案信息资源, 为地方的经济 转型服务。

完善管理体制, 实现档案资源信息化、科技化与网络化。 创造档案信息资源共享的高效平台。主动创建推动高校档案 资源服务地方经济和社会发展的内外环境。充分发挥档案的 经济性, 使档案工作适应社会发展的需要, 开发利用档案信 息资源社会化, 档案中的科研成果信息得到有效推广, 进一 步激活档案工作的运行机制, 充分发挥档案的社会效益和经 济效益。因此, 要充分发挥档案的经济性, 就要把档案馆网建 设成为布局合理、分工明确、馆藏丰富、具有现代化管理手 段和综合开发档案信息资源的有机整体,切实为地方的经济 转型和社会发展提供优质服务。

\section{5 结语}

国务院办公厅曾下发《关于加快众创空间发展服务实体 经济转型升级的指导意见》, 其中指出鼓励高校围绕优势专 业开放资源共享等问题。新时期对档案管理提出了许多新的 要求, 同时也给档案工作带来了机遇和挑战。我们要以 “服 务经济转型发展” 为目标, 在创新的道路上, 以实事求是的态 度, 不断探索实践, 提高挖掘和利用的水平, 在为地方经济转 型和社会发展服务的同时创新发展高校档案工作。

\section{[参考文献]}

[1] 陈永生.档案工作效益论 [M].北京:中国档案出版社,1995:8-9.

[2]陈一红.地方高校档案资源服务区域经济建设浅论 [J].经济视角,2011(02):136-137.

[3]刘晓丽.充分利用档案信息资源为地方经济建设服务 [J].高教论坛,2013(3):88-89.

\section{作者简介：}

闵丽娟(1979--), 女, 辽宁西丰人, 汉族, 硕士, 助理馆员, 研 究方向：档案管理。 